\title{
Teletrabajo, COVID-19 y el ejercicio regular de la función empresarial como forma de resguardar también los derechos de quienes prestan servicios
}

\author{
Telecommuting, COVID-19 and the regular \\ exercise of the business function as a way \\ of also safeguarding the rights of those \\ who provide services
}

\section{Adolfo Nicolás Balbín 1 \\ Universidad Nacional de La Plata - Argentina}

Revista Derechos en Acción ISSN 2525-1678/ e-ISSN 2525-1686

Año 5/Nº 17 Primavera 2020 (21 septiembre a 20 diciembre), 643-658

DOI: https://doi.org/10.24215/25251678e472

Recibido: 01/09/2020

Aprobado: 10/12/2020

Resumen: En el presente artículo, escribo unas breves líneas vinculadas con la implementación del teletrabajo en el contexto del COVID-19, adicionando algunas de sus proyecciones. A su respecto, luego de ubicar a la nueva modalidad del contrato laboral en aquel marco pandémico, menciono los beneficios individuales que ella trae consigo, para luego dar cuenta acerca de ciertos límites que, primero desde una visión bilateral del trabajo, y luego desde una mirada plurilateral del mismo, igualmente deben ser considerados. Mi hipótesis es que si bien la figura del teletrabajo supone la recepción de un instituto muy útil no solo en los tiempos que corren sino también para los sucesivos mejores momentos,

Abogado (UNLP). Especialista en Derecho Social -del trabajo y la previsión- (UNLP). Especialista en Derecho Administrativo (UNLP). Profesor Adjunto en Derecho Social, Facultad de Ciencias Jurídicas y Sociales, UNLP. Correo electrónico: nicolasbalbin@hotmail.com (ORCID: https://orcid.org/0000-0003-2927-2918). 
la misma debiera ser aplicada de forma controlada y razonable, a fin de que, a la par que genera beneficios para las empresas, no suponga un ejercicio irregular de los poderes de dirección que, en aquellas, se les reconoce a los empleadores. La conclusión central a la que arribo es que si bien hay que tomar en cuenta los beneficios que puede conllevar la utilización de la nueva modalidad del contrato laboral, también se debe considerar su utilización adecuada para no perjudicar a los trabajadores.

Palabras clave: teletrabajo, COVID-19, derechos laborales, ejercicio regular de la función empresarial.

Abstract: In this article, I write a few brief lines related to the implementation of telework in the context of COVID-19, adding some of its projections. In this regard, after locating the new modality of the labor contract in that pandemic framework, I mention the individual benefits that it brings with it, to then give an account of certain limits that, first from a bilateral view of work, and then from a plurilateral view of the same, should also be considered. My hypothesis is that although the figure of telework supposes the reception of a very useful institute not only in current times but also for successive best moments, it should be applied in a controlled and reasonable way, so that, at while it generates benefits for companies, it does not imply an irregular exercise of the management powers that, in those, are recognized by employers. The central conclusion that I arrive at is that although the benefits that the use of the new form of the labor contract may entail must be taken into account, its proper use must also be considered so as not to harm workers.

Keywords: teleworking, COVID-19, labor rights, regular exercise of the business function.

\section{Introducción}

A través de este desarrollo, pretendo efectuar una contribución que sirva para el estudio y la comprensión de la figura del teletrabajo, partiendo para ello de la actual y especial situación sanitaria, mas sin que dicho punto de inicio suponga la limitación de las eventuales conclusiones al contexto crítico actual, 
sirviendo en todo caso el dato apuntado como un puntapié para las posteriores explicaciones.

En ese marco, aquí se articulan una serie de elementos provenientes tanto de la Ley de Contrato de Trabajo nro. $20.744^{2}$ que vertebra las relaciones individuales obrero patronales en nuestro país, como de la reciente Ley $27.555^{3}$ que incorporó, como nueva modalidad contractual, al teletrabajo, insertando a su vez algunas otras precisiones respecto a la mentada figura, y remitiendo a lo que, en lo sucesivo, deberán reglamentar las fuentes específicas en la materia.

La hipótesis de la cual parto es que si bien la figura del teletrabajo supone la recepción de un instituto muy útil no solo en los tiempos que corren sino también para los sucesivos mejores momentos, la misma debiera ser aplicada de forma controlada y razonable, a fin de que, a la par que genera beneficios para las empresas, no suponga un ejercicio irregular de los poderes de dirección que, en aquellas, se les reconoce a los empleadores.

En ese íter, me concentro aquí en escribir algunas breves líneas que tiendan a proteger a la persona que presta servicios, frente a un eventual ejercicio extralimitado de los poderes antes mencionados, ello con foco en la jornada laboral y en las tareas que se le pueden encomendar al trabajador.

Para lo posterior, adelanto que en este trabajo utilizo las palabras contrato de trabajo, relación laboral y vínculo apropiativo, como sinónimos.

\section{Coronavirus, teletrabajo, y una útil regulación legal}

La pandemia del COVID-19 por la que lamentablemente todos estamos atravesando, ha provocado innumerables daños en las sociedades del mundo (entre las que obviamente también debemos incluir a la nuestra), y ha generado a su vez

\footnotetext{
2 B.0. 27/09/1974.

3 B.0. $14 / 08 / 2020$.
} 
la necesidad de reorganizar muchos aspectos de las mismas, dentro de los que cabe reparar ahora, como objeto especial de este aporte, en el desarrollo de la actividad productiva y, con ella, el desenvolvimiento de los contratos de trabajo.

Sin duda alguna los sectores productivo y laboral han sido de los que mayores afectaciones recibieron en relación con la circunstancia sanitaria antes apuntada. En efecto, focalizando el análisis únicamente a nuestro país, si bien la crisis económica se ha vuelto estructural en los últimos años -a raíz de lo cual se dictaron varias normativas especiales (por ejemplo la Ley nro. $27.541^{4}$ de solidaridad social y reactivación productiva en el marco de la emergencia pública)-, lo cierto es que la propagación vertiginosa del coronavirus, en paralelo con la declaración internacional del estado de emergencia sanitaria por parte de la OMS hacia principios del mes de marzo del corriente año, ha intensificado la crisis aludida, provocando su expansión incluso a otras arenas tales como la política, el trabajo, la educación, el deporte, etcétera.

Producto de tal estado de situación de hondo calado, y como ya lo adelantara anteriormente, se ha impuesto la presurosa necesidad de reorganizar las actividades empresariales cual forma de intentar adaptarse a las nuevas y funestas circunstancias del medio, continuando con la actividad productiva.

Ese imperioso requerimiento hizo que se activaran, en paralelo a los álgidos ánimos sociales y económicos, dispositivos que permitieran sobrellevar los tan complejos tiempos que todos estamos viviendo, dinamizándose lentamente, entre ellos, la figura del teletrabajo, institución que obligó a desempolvar viejos debates, engrosándolos con otros nuevos que tuvieron como foco muchas actividades y regímenes jurídicos en nuestro país. En medio de ello, tal como lo adelantara en la introducción del presente, recientemente se ha sancionado la Ley 27.555 que incorporó la figura del teletrabajo a la LCT 20.744, como una nueva modalidad del vínculo jurídico y personal laboral.

4 B.0. 23/12/2019. 
Avanzando, es útil traer a colación en ese estadío un concepto inserto en la nueva ley antes apuntada, en cuanto reza: "Habrá contrato de Teletrabajo cuando la realización de actos, ejecución de obras o prestación de servicios, en los términos de los artículos 21 y 22 de esta ley, sea efectuada total o parcialmente en el domicilio de la persona que trabaja, o en lugares distintos al establecimiento o los establecimientos del empleador, mediante la utilización de tecnologías de la información y comunicación" (artículo 2 de la misma, actual artículo 102 bis, primer párrafo, de la LCT).

Cabe reparar aquí en que la figura del teletrabajo, si bien ya ha sido tratada jurídicamente con anterioridad a la pandemia provocada por el coronavirus, recibió un importante envión a partir del nuevo estado de situación en el que razones sobre todo de tipo sanitarias impidieron e impiden la normal prosecución de la relación de trabajo. En efecto, usualmente la vinculación laboral -que parte de un acuerdo inicial (al menos en lo que hace a los elementos centrales de la contratación)-, adquiere cuerpo a partir de la puesta a disposición, en la empresa, de la fuerza productiva que como capital humano aporta el trabajador, activándose paralelamente el haz de derechos y obligaciones que titulariza el empleador.

Sin embargo, aquella forma habitual de desarrollar el contrato de trabajo hoy se ha complejizado, debido a que razones sanitarias impiden o bien limitan la presenciabilidad de quienes deben cumplimentar la central obligación de cumplimiento que mencioné en el párrafo anterior.

Frente a ello, en muchas actividades se ha desarrollado, con una velocidad menor que la actual pandemia, la modalidad de prestación laboral en base al teletrabajo. La diferencia mencionada se debe a que si en la propagación del COVID-19 intervienen directamente factores biológicos y naturales que exceden la propia intención de la persona, para la introducción de una figura jurídica de especiales e incluso novedosos contornos como el teletrabajo, se requiere tomar en cuenta otros 
factores como la planificación y la regulación normativa, la gran diversidad de entornos productivos, la disparidad económica de cada uno de los sectores, el nivel de instrucción de las personas, entre otros. En lo que sigue, avanzaré un poco más respecto a lo dicho, primero focalizando el alcance del teletrabajo desde una óptica metodológica legal, para luego proseguir dándole mayor protagonismo a la hipótesis ya escrita.

\section{Teletrabajo como una nueva modalidad del contrato laboral. Alcances}

Como ya ha sido planteado por mucha y variada doctrina nacional ${ }^{5}$, constituyendo lo dicho una base bastante estable para el conocimiento de la relación existente entre un trabajador y un empleador, en el derecho del trabajo, y en lo que hace a las figuras reguladas en el Título III de la LCT, la palabra modalidad no supone la inserción en la anterior relación de intercambio de una figura que sujete la perfección del negocio a una especial situación relacionada con el tiempo, el cumplimiento de un acto, o la materialización de una futura circunstancia más o menos conocida (hago referencia al plazo, al cargo y a la condición, todas provenientes del derecho común de fondo ${ }^{6}$ ) susceptibles de reducir la eficacia del vínculo celebrado, sino que en la materia laboral la palabra modalidad -siguiendo la línea trazada por el legislador en el apartado de la LCT antes mencionado-, da cuenta de la presencia de un negocio que se ha celebrado con características distintas al contrato promovido o por tiempo indeterminado, cuyas cualidades centrales y típicas son que se vertebra a partir de prestaciones individuales y continuadas tanto del trabajador como del empleador, prolongándose, como

\footnotetext{
5 A modo de ejemplo, se pueden consultar las siguientes obras: Tratado de derecho del trabajo, Mario E. Ackerman (Director), Diego M. Tosca y Alejandro Sudera (Coordinadores), Tomo II, página 459 y siguientes, 2014, Santa Fe, editorial Rubinzal Culzoni; Derecho del Trabajo. Manual de las relaciones individuales, Ángel E. Gatti, página 197 y siguientes, 2015, Buenos Aires, editorial BdeF.
}

6 Ver regulación existente en el Código Civil y Comercial de la Nación, artículos 343 a 357. 
regla, hasta que la persona que pone su fuerza de trabajo a disposición de la otra se encuentra en condiciones de jubilarse.

En ese marco, y en líneas generales, una modalidad contractual laboral se corporiza cuando el vínculo que une a quien trabaja y quien emplea no reúne alguna de las anteriores cualidades, ya sea porque se celebra por un tiempo menor omitiendo la extensión de la relación hasta la jubilación del trabajador -contrato a plazo fijo-, porque no supone ordinariamente la materialización individual de la prestación -contrato por equipo-, porque no refiere a prestaciones centrales continuadas de ambas partes - contrato de temporada- o bien porque sujeta la prolongación del tracto apropiativo al cumplimiento de un evento futuro e incierto -contrato eventual típico-.

Sin perjuicio de ello, como antes lo dije, en el derecho del trabajo una modalidad no crea un negocio imperfecto (como sí ocurre en la regulación que proviene del ordenamiento civil y comercial), sino que, contrariamente a ello, desde el inicio el vínculo reúne todas las características centrales que cimentan las obligaciones de cumplimiento (prestaciones centrales de ambos contratantes, a saber, poner la fuerza de trabajo a disposición del otro y, como contrapartida, pagar el salario) y de conducta (obligaciones importantes también, aunque con el papel de coadyuvantes de aquellas, por ejemplo, el obrar con buena fe, el deber de solidaridad y colaboración, la debida diligencia, la reserva de los secretos empresariales), mas transitando las mismas en un terreno distinto al que conforma el contrato por tiempo indeterminado.

Desde esta óptica, cabe reparar ahora en el alcance del teletrabajo como una nueva modalidad contractual. A mi modo, dicho encuadre se acredita plenamente, puesto que a diferencia del vínculo típico laboral en el que el cumplimiento de la obligación central del trabajador o trabajadora (poner su fuerza de trabajo a disposición de quien emplea) se materializa de forma presencial, en la nueva figura incorporada a partir de la Ley 27.555 se reconoce la posibilidad de variar aquella exigencia, 
reconociéndole a las partes la posibilidad de acordar y llevar a cabo el desarrollo de aquella obligación "total o parcialmente en el domicilio de la persona que trabaja, o en lugares distintos al establecimiento o los establecimientos del empleador", dato al que se adiciona "la utilización de tecnologías de la información y comunicación", tal como ya fuera puesto de manifiesto antes, al transcribir el actual artículo 102 bis de la LCT.

Como se puede observar, los elementos típicos del teletrabajo como nueva modalidad contractual son la no presenciabilidad, total o parcial, del trabajador en la empresa o establecimiento del empleador, y el uso de las TICs. Ello así, al no tocar única y directamente al contrato promovido, sino también al resto de las modalidades referidas, puede resultar eventualmente transversal a todas ellas, en el sentido de que a partir de la entrada en vigencia de la ley 27.555 (que se operativizará "luego de noventa (90) días contados a partir de que se determine la finalización del período de vigencia del aislamiento social, preventivo y obligatorio" tal como lo reza su artículo 19), cualquiera de las formas contractuales referenciadas antes (y otras más como por ejemplo el contrato a tiempo parcial) podrán recibir las incidencias de la figura del teletrabajo.

\section{La incorporación de una novel figura legal, junto a la continuidad de la exigencia atinente al cumplimiento regular de la función empresarial}

Prosiguiendo, cabe reparar ahora en ciertos elementos que, sobre la base de la hipótesis trazada al inicio, dan cuenta de la importancia de tomar nota, en la introducción del teletrabajo, del regular ejercicio de ciertas funciones contractuales típicas de los empleadores.

A su respecto, dentro del campo jurídico, cabe reparar en ciertos alcances que a mi modo debieran tomarse en cuenta al momento de analizar el nuevo dispositivo prestacional laboral del que antes hice mención. Para ello, clarificando la metodología siguiente, diré que efectúo una separación entre 
las órbitas unilaterales (haciendo una breve mención de ciertos efectos que tanto para el trabajador como para el empleador, individualmente considerados, supone el teletrabajo), en la bilateral (aquí me concentro en algunos elementos que provienen del vínculo conmutativo trabajador-empleador) y plurilaterales (incorporando en esta última a ciertos elementos que toman por foco de análisis, y en general, a todos los contratos vigentes en una empresa).

En primer término, y desde una visión eminentemente unilateral, remarco que el teletrabajo como nueva modalidad dentro del contrato laboral (tal como la tipifica el artículo primero de la flamante Ley $27.555^{7}$ ), ha venido a cumplir en los especiales tiempos que corren una función central, cual es la de permitir continuar la actividad productiva de la empresa, introduciendo ciertos componentes especiales a aquella forma de vinculación jurídica. En esto cabe tomar en cuenta que si bien no todas las empresas ni todas las actividades de la misma pueden adaptarse a esta particular forma de prestación de servicios (ya sea porque se requiere de la presencia de los trabajadores en la empresa, o bien porque no se cuenta con la base organizativa o económica suficiente como para costear los gastos que supone la nueva modalidad, o porque median barreras cognitivas que impidan una rápida adaptación a la prestación a distancia), lo cierto es que les ha permitido, en un corto período de tiempo, tener disponible una alternativa con que poder continuar produciendo aún frente al distanciamiento social decretado.

Por su parte, esta nueva modalidad también ha favorecido a muchos trabajadores, debido a que, si no median los impedimentos arriba enunciados, pueden continuar prestando servicios, conservar su fuente laboral, y resguardar su salud frente a la expansión del coronavirus así como también de otras enfermedades propias del clima.

\footnotetext{
7 A su respecto, dicho precepto establece que: "La presente ley tiene por objeto establecer los presupuestos legales mínimos para la regulación de la modalidad de Teletrabajo en aquellas actividades, que por su naturaleza y particulares características, lo permitan".
} 
Sin embargo, en el análisis del teletrabajo como nueva modalidad prestacional laboral cabe tener presente, también, ciertos elementos que en sintonía con el principio protectorio como parte natural del derecho del trabajo, deben necesariamente considerarse a los fines de evitar perjuicios en la persona que cumple servicios por cuenta ajena.

Primero, y adentrándome ahora en el campo de la bilateralidad, advierto que paralelamente al buen desempeño que debe exigirse del trabajador, la implementación de la modalidad del teletrabajo debe resguardar los derechos del último frente a ciertos comportamientos de los empleadores que puedan suponer la alteración de alguno de los límites con que se entiende debe interpretarse y aplicarse la nueva figura laboral.

Así, de la Ley 27.555 surge que las regulaciones especiales que a su respecto se sancionen deben respetar los principios de orden público establecidos en la ley (artículo 2, incorporado como 102 bis a la LCT), y que las personas que prestan servicios mediante teletrabajo gozan de los mismos derechos y obligaciones que aquellas que lo hacen de forma presencial (art. 3).

En función de dicha base, y considerando el alcance de los institutos laborales de fondo, la laxitud de la obligación de concurrencia a la empresa no puede suponer, contrariamente, la reducción de los derechos de los trabajadores.

Uno de los ítems más sobresalientes en aquel punto atañe a la jornada de trabajo, período de tiempo en el cual el trabajador debe encontrarse a disposición del empleador en tanto no pueda usar del mismo en beneficio propio (art. 197, primera parte, de la Ley de Contrato de Trabajo nro. 20.744). Dentro de este tema, se enlista otro importante que hace a la nueva modalidad puesta en práctica en los últimos tiempos a raíz de la pandemia de público conocimiento, el que, vinculado a la extensión de la jornada, permite alzarnos contra una eventual errónea interpretación que suponga que el cumplimiento de la prestación desde el hogar -y a partir de los dispositivos que formen parte de la propiedad de quien labora, o bien que sean 
brindados por el empleador-, concretiza una puesta a disposición permanente en beneficio del último, entendiéndose allí que la tecnología funcionaría como una puerta sin herraje para la prestación de servicios en beneficio de la empresa, y dando origen a una irregularidad en lo que hace al tiempo fijado legal o convencionalmente para estar a disposición de quien paga el salario. En este punto, el segundo párrafo del artículo 5 de la Ley 27.555 regula que: "El empleador no podrá exigir a la persona que trabaja la realización de tareas, ni remitirle comunicaciones, por ningún medio, fuera de la jornada laboral", incorporándose en la primera parte del mentado precepto a la desconexión digital como derecho de los trabajadores, ya sea que la misma propenda al descanso diario, o bien a la utilización de su derecho a las licencias pertinentes ${ }^{8}$.

Relacionado con lo anterior, creo conveniente traer a cuenta otro punto que no ha sido incorporado expresamente en la Ley 27.555, pero que, sin embargo, a mi modo tiene mucha importancia, pues se vincula con la obligación del empleador de dar al trabajador tareas acorde con la jornada legalmente fijada. En ese punto, no se puede exigir que la persona que presta servicios a través del teletrabajo realice actividades que superen con notoriedad las que se puedan cumplir en una jornada habitual de empleo. Aquí, remarco la necesidad de distinguir aquellos actos voluntarios por medio de los cuales los trabajadores realizan actividades de la empresa en sus casas aún fuera de la jornada de trabajo, de aquellas otras situaciones en las que se les impone la exigencia de prestar servicios o encontrarse al menos a disposición por fuera de aquella limitación, sin que medie a su respecto una situación de peligro o emergencia para los bienes de la empresa, y que requiera, con carácter

8 Respecto a la desconexión digital, la Ley 27.555 dice que: "La persona que trabaja bajo la modalidad de teletrabajo tendrá derecho a no ser contactada y a desconectarse de los dispositivos digitales y/o tecnologías de la información y comunicación, fuera de su jornada laboral y durante los períodos de licencias. No podrá ser sancionada por hacer uso de este derecho". 
extraordinario, la prolongación de la jornada laboral. Entiendo así, que ésta es otra de las situaciones que, en resguardo a los derechos de las personas que prestan servicios, se deben tomar en cuenta en los especiales tiempos que corren, atravesados por la extensión de la modalidad del teletrabajo.

Superando aquella órbita bilateral -y sin que lo escrito suponga omitir la existencia de los otros derechos ordinarios emanados de la relación contractual-, quiero ahora escribir algunas cuestiones atinentes al ámbito plurilateral, también involucrado en el campo del teletrabajo. Como ya lo adelanté, aquí utilizo la palabra plurilateral para referenciar ya no una sola relación de empleo, sino todas las que existan en el seno de una misma empresa.

En este campo, a mi modo resulta crucial reparar en el deber que el empleador tiene de conferir igual trato, y sobre todo de formalizar similares exigencias, a todos los trabajadores que prestan servicios en la empresa, evitando distinciones que no tengan por base, seriamente, la categoría contractual de cada uno.

Desbrozando lo anterior, si bien reitero los beneficios del teletrabajo, entiendo que dicha modalidad contractual no puede ser la base de un desigual trato del empleador para con todos y cada uno de sus trabajadores, ya sea sobrecargando de tareas a quienes prestan servicios en sus domicilios, o bien a aquellas personas con las que se acordó la prestación de tipo personal en la empresa, incluyéndose en esa categoría -a mi modo- la sobrecarga con entidad como para dañar a alguna de las dos personas, reduciendo de manera arbitraria las exigencias de quienes laboran en sus domicilios o de aquellos que lo hacen en el establecimiento del empleador.

En tal marco, es dable recordar que la LCT contiene varios preceptos que impiden alguna de las anteriores conductas. Así, el artículo 17 preceptúa: "Por esta ley se prohíbe cualquier tipo de discriminación entre los trabajadores por motivo de sexo, raza, nacionalidad, religiosos, políticos, gremiales o de edad"; y en la misma senda, el artículo 81 regula que: "El empleador 
debe dispensar a todos los trabajadores igual trato en identidad de situaciones. Se considerará que existe trato desigual cuando se produzcan discriminaciones arbitrarias fundadas en razones de sexo, religión o raza, pero no cuando el diferente tratamiento responda a principios de bien común, como el que se sustente en la mayor eficacia, laboriosidad o contracción a sus tareas por parte del trabajador".

A su respecto, como lo ha planteado buena doctrina ${ }^{9}$, cabe reparar en que los motivos discriminatorios mencionados por las normas antes transcriptas suponen una simple enunciación, por lo que se pueden incluir otros como por ejemplo los atinentes a las modalidades contractuales. En igual camino, si bien el artículo 81 de la LCT refiere a la identidad de situaciones a los fines de hacer mención a la obligación patronal atinente a la dispensa de trato igual, considero que no puede asumirse (en lo que hace a la temática de este aporte doctrinario) que la implementación del teletrabajo como forma de prestación a distancia de la fuerza laboral suponga la concreción de una razón de tipo objetiva que permita tratar de forma desigual a los trabajadores de la empresa. En dicha senda, no puede admitirse -para la interpretación del vínculo laboral, junto a los derechos y obligaciones que del mismo emanan- que la implementación de distintas modalidades en el seno de una misma empresa (tareas presenciales junto con tareas a distancia) o bien la organización de la producción completamente a distancia, se constituya en una causa suficiente como para otorgar un trato injustificadamente desigual a los trabajadores a cargo, ello por cuanto conforme a la LCT (que ahora se cita como normativa general de las relaciones individuales de trabajo) únicamente se permiten diferencias basadas en razones de bien común, mayor eficacia, laboriosidad o contracción a las tareas por parte del trabajador, sin que se incluya en ninguna de ellas a la basada en una modalidad laboral.

9 Ver: López, J., Centeno, N., Fernández Madrid, J.C. (1977). Ley de contrato de trabajo comentada. Buenos Aires, edit. Contabilidad Moderna, tomo 1, página 397 y siguientes. 
Lo dicho a su vez tiene una base profunda en el deber de actuar con buena fe, colaboración y solidaridad dentro la empresa (conf. arts. 62 y 63 de la LCT), e implica que el ejercicio de los poderes de dirección del empleador no solo debe ser funcional, atendiendo en este tramo a los fines de la empresa, sino que también debe propender a la preservación y mejora de los derechos personales y patrimoniales de quien presta servicios (art. 65 de la LCT).

En línea con lo desarrollado en este punto, cabría subrayar el precepto contenido en la última parte del artículo 18 de la Ley 27.555 que remite a los preceptos atinentes al sistema de inspección del trabajo que se encuentran regulados en la Ley $25.877^{10}$ (Título III, Capítulo I) y modificatorias, ello sin olvidarnos de la exigencia de cumplimiento regular que, desde el inicio de la vinculación, grava a las voluntades de ambas personas contratantes. Es decir, si al Estado le corresponde ejercer con suficiencia la función de contralor respecto al cumplimiento adecuado de las leyes laborales, ello no omite, ni borra ni debilita, la central obligación de quienes celebran un contrato respeto al acatamiento de la ley.

\section{Algunas conclusiones a modo de cierre}

Como palabras finales diré que la pandemia provocada por el COVID-19 ha traído consigo muchas consecuencias sociales y jurídicas, entre ellas la regulación del teletrabajo como nueva modalidad contractual en la LCT.

En eso, si bien con anterioridad a la Ley 27.555 existieron varios proyectos que trabajaron en torno a la modalidad antes mencionada, resulta indudable que el actual contexto sanitario nacional e internacional sirvió de envión para la aceleración del estudio e incorporación de una nueva figura legal que propendiera, al menos, a tratar de dinamizar los procesos productivos

10 B.0. 19/03/2004, de "Ordenamiento del Régimen Laboral". 
y el desarrollo de las relaciones laborales, dos focos centrales golpeados profundamente por los efectos nocivos derivados del globalizado contagio del virus ya mencionado.

Sin perjuicio de lo precedente, entiendo que debemos proyectar al teletrabajo, también, por fuera de los márgenes atinentes al coronavirus, puesto que si bien la actual pandemia ha incidido para su tratamiento y reconocimiento legal a nivel nacional, y a través del cuerpo legal que vertebra las relaciones individuales obrero patronales, los efectos derivados de la nueva modalidad de trabajo y empleo continuarán vigentes con las modificaciones o reglamentaciones que, a futuro, se crea necesario incorporar, incluso una vez superada la actual y compleja situación de salud.

Desde ese aspecto, también se debe estudiar al teletrabajo como una figura que pretende modernizar las relaciones de apropiación laboral. Y, en ese marco, seguramente la misma tendrá un desarrollo importante en nuestra sociedad, a partir de las regulaciones que busquen mantener el equilibrio de los intereses encontrados en la misma, y las reacciones antecedentes o sobrevinientes.

Sin embargo, más allá de ciertos detalles contenidos en la Ley 27.555 (y que no fueron desarrollados en este trabajo, puesto que el objetivo central aquí fue subrayar únicamente algunas cuestiones entendidas como centrales para la inicial implementación, y control, del teletrabajo), lo cierto es que cabe mirar con especial atención a lo que suceda con el ejercicio de las facultades empresariales, en los terrenos vinculados con la jornada laboral y con las tareas encomendadas a los trabajadores, materias que, a mi modo, son las que generan una mayor inquietud.

En línea con ello, si bien celebro la incorporación del teletrabajo como una modalidad tendiente, en el corto plazo, a tratar de paliar los efectos negativos del contexto, provocadores de importantes crisis empresarias -ello junto a la ya mencionada proyección futura de dicha figura- considero que aquella forma 
contractual debe ser llevada a la práctica de forma adecuada, procurando que, a la par que se crea una alternativa de prestación para no afectar tanto a la actividad productiva y laboral, los trabajadores no sean perjudicados por un ejercicio irregular de las funciones otorgadas a los empleadores. 